\title{
Mobile Applications as Carriers of Institutional Pressures: A Case of the Finnish Taxi Industry
}

\author{
Karin Väyrynen ${ }^{1}$, Arto Lanamäki ${ }^{1}$, and Juho Lindman ${ }^{2}$ \\ ${ }^{1}$ Interact research unit, Faculty of ITEE, University of Oulu, \\ PO Box 8000, FI-90014 Oulun yliopisto, Finland \\ ${ }^{2}$ Applied Information Technology, University of Gothenburg \\ Gothenburg, Sweden \\ karin.vayrynen@oulu.fi; arto.lanamaki@oulu.fi; \\ juho.lindman@ait.gu.se
}

\begin{abstract}
While the worldwide market expansion of Uber has raised controversy, Uber has also received praise for its mobile phone app. Its many features - taxi ordering, pricing, real-time location information, paying, and service evaluation - have provided significant customer value. When Uber entered Finland in November 2014, few other taxi apps were available. Between 2014 and 2018, this shortage of taxi apps turned into an abundance, with many companies introducing their own taxi apps. By leaning on institutional theory, and more specifically by applying coercive, mimetic and normative pressures as a lens, we provide an explanation for why three Finnish taxi apps now resemble Uber in some features, whereas they differ in others. Based on our interviews, we can explain the present-day differences between these apps by coercive and normative pressures in the institutional environment of the Finnish taxi industry. We contribute to the IT and institutionalization research stream by illustrating how mobile applications as IT artefacts can be seen as carriers of institutional pressures materializing in the features they provide.
\end{abstract}

Keywords: taxi industry, institutional pressures, mobile apps

\section{Introduction}

The fame of the transportation network company Uber is mostly associated with its affordable "ridesharing" service UberX (known as UberPop in some markets) [1]. Uber's worldwide expansion has fueled controversy [2] and the company's ethics have been questioned [3, 4]. Yet, Uber's mobile app is generally viewed as an impressive technological achievement [5]. Largely due to Uber, the taxi industry is now one of the most well-known examples of industry-transforming digital disruption [2,5].

Theories of organizational institutionalism have discussed change and stability when evaluating the impacts of digital technologies in various industries. Earlier research has treated these technologies as exogenous change forces, but a more nuanced understanding of their endogenous role has recently emerged [6].

Studies on institutional theory have shown that firms face multiple institutional pressures that are often incompatible with each other [7]. Gosain [8] argues that institutional logics are encoded into IT systems. Rajão and Hayes ([9], p. 328) formulate 
that "institutional theory can provide an important theoretical lens to provide a historical understanding of the ways in which specific IT artefacts come about and change over time". They look at the institutional context in form of conceptualizations of control and argue that there is a dialectic relationship between the institutional context and the IT artefact. IT artefacts are "bundles of material and cultural properties packaged in some socially recognizable form such as hardware and/or software" ([10], p. 121). Along these lines, mobile taxi hailing applications represent such IT artefacts.

The institutional environment of Finnish taxi firms has been heavily regulated. Finland has one of the tightest barriers to entry in the taxi market in the EU [11]. The number of taxi licenses is limited and the maximum price for taxi rides is regulated by the state. Taxi drivers have to pass a test and are required to use the official taximeter in their cars. Thus, the institutional environment for taxi hailing organizations and their IT artifacts in form of mobile apps is especially interesting in Finland. In November 2014, Uber entered the Finnish taxi market. Between November 2014 and the present day (February 2018), several mobile taxi hailing applications have been introduced in Finland by existing Finnish taxi companies.

Leaning on Rajão and Hayes [9], we wondered how the institutional context in a form of different institutional pressures in Finland can help explain the similarities, but also the differences between three Finnish taxi hailing apps and Uber. We ask the following research question:

How are institutional pressures implicated in the feature functionalities in taxi hailing apps in the Finnish market?

Our main contribution is to show that applying the lens of institutional pressures can help explain why mobile apps that were created for similar purposes resemble each other in some features, while they differ in other features. We illustrate how IT artefacts in form of mobile apps can be seen as carriers of institutional pressures.

\section{Theoretical Background}

We ground our study in literature on institutional theory, and more specifically, on institutional pressures, and the inscription of institutional values into IT artefacts.

Institutional theory helps explain why organizations within a certain institutional environment resemble each other. Institutions mean regulative, normative, and cognitive structures and activities that provide stability and meaning to social behavior [12]. Organizations operate in institutional environments, and in order to receive legitimacy and support they have to conform to the rules and requirements of these environments. Institutional isomorphism means that firms subscribe to the same institutions within their field [13], and that organizations/units resemble other units in that same environment. Three forms of institutional pressures/forces that lead to institutional isomorphism can be distinguished: coercive, normative, and mimetic [13].

Coercive pressures are results of politics and power relationships in the society. Actors such as the state require compliance in practices threatening with formal and informal sanctions. In coercive isomorphism, companies of an industry show similarities to each other because of certain regulative or legal pressures. Normative 
pressures are results of what is considered proper course of action and often related to professional values. In normative isomorphism, change is influenced by professional standards or networks. Mimetic pressures are a reaction to uncertainty: organizations follow examples that are evaluated as being successful. In mimetic isomorphism, thus, a company imitates another company because of assuming that the other company's structure is somehow beneficial. Regulative pressures often come top-down from governments, whereas mimetic pressures are result of peer-pressure from other companies and normative pressures come from professional groups primarily from inside organizations [14].

IS research has also applied institutional theory extensively. Mignerat and Rivard [15] analyzed 53 IS studies that use institutional theory. They identified entities from which institutional pressures arise from in four stages of IS innovation. They found that coercive pressures arise from, e.g., governments, regulatory agencies and industry associations, normative pressures from, e.g., technology suppliers, industry and trade associations and consultants, and mimetic pressures from, e.g., peers, successful organizations, and competition.

Researchers have brought IT artefacts into the study of institutional theory. Rajão and Hayes [9] identified four research streams regarding the relationship between organizations and IT artifacts: 1) why organizations still invest into IT even though no clear evidence exists about increased efficiency and return-on-investment, 2) IT innovations, 3 ) the inscription of institutional values into IT artefacts, and 4) the role of IT artefacts in change processes. Our research falls into the third category. Rajão and Hayes ([9], p. 321), building on [16], summarize that "the context of institutions find their way into the design of IT artefacts, which in turn also become institutional carriers that help to support and reproduce certain institutional arrangements".

In the present paper, we study how institutional pressures are implicated in the features of three Finnish taxi-hailing apps.

\section{Research methods and context}

\subsection{Research methods}

We conducted this research as a case study, which is a suitable approach in addressing "how" and "why" questions about a contemporary phenomenon [17]. As the current research asks how institutional pressures are implicated in different features of taxi hailing apps available in the Finnish market, case study is a suitable research method.

Case background. This paper is part of a research program investigating digitalization in the Finnish taxi service industry. In the present study, we compare the features implemented in three Finnish taxi apps to the traditional taxi service model on the one hand, and the Uber app on the other hand. We selected these three apps as they are by far the "largest" ones in Finland when looking at the number of taxis that can be reached with the applications. App $\boldsymbol{A}$ (7500 taxis in 200 municipalities in Finland) has been launched in 2015 and works nationwide. App B (1250 taxis in Southern Finland) was launched in June 2015 by a taxi dispatch center that dispatches rides in 19 cities in Southern Finland. App $\boldsymbol{C}$ (1335 taxis in Southern Finland) has been launched by Southern Taxi (a pseudonym) in November 2017. Before that, Southern Taxi had 
already another mobile app (Delta App) with much more restricted feature functionalities than App C. Southern Taxi used App A in parallel to the Delta App for almost 2 years but separated from App A in November 2017.

Table 1. List of interviewees (anonymized).

\begin{tabular}{lll}
\hline$\#$ & Title & Organization \\
\hline 1 & Executive manager & FTOF \\
2 & Executive manager & FTOF \\
3 & Manager & FTOF \\
4 & Executive manager & Technology provider for FTOF \\
5 & Manager & Southern Taxi \\
6 & Executive manager /Developer & Technology provider for Southern Taxi \\
7 & Executive manager & Northern Taxi \\
8 & Executive manager & Northern Taxi \\
9 & Representative & Uber Finland \\
10 & Lobbyist & A PR Agency \\
11 & Representative & Taxify \\
12 & Executive manager & A regional taxi service association \\
13 & Executive manager & A regional taxi service company \\
14 & Executive manager & Transportation service company \\
15 & Executive manager & A technology provider \\
16 & Chief of licensing & A public sector organization \\
17 & Entrepreneur & A technology provider \\
18 & Expert & A mobility association \\
\hline & &
\end{tabular}

Data collection. We collected publicly available information on the features of App $\mathrm{A}, \mathrm{B}$ and $\mathrm{C}$ and Uber from the respective websites of the applications. We have read histories of the taxi service industry in Finland (e.g., [18]) and elsewhere (e.g., [19]). Moreover, we have followed public discussion on the media concerning the taxi service industry. In addition, we conducted 17 interviews with 18 interviewees (one interview was a group interview with 2 interviewees) with an average length of 88.4 minutes (see Table 1). Interviewees were representatives of the taxi companies of App A and App $\mathrm{C}$, technology providers of App A and App C, representatives of Uber Finland, as well as dispatch centers who use(d) App A. In addition, we interviewed representatives of other taxi companies and taxi industry stakeholders in Finland. For anonymization reasons, we are not able to give more detailed information about which interviewee represented which company. Our comparison of the features of App A, B, C and Uber is mainly based on publicly available information. Our understanding of the institutional environment in which App A-C were developed is based on the interviews.

Data analysis. In the data analysis, we made use of the five aspects of the basic process related to ride sourcing platforms [5] that are relevant to the customer. These five aspects are 1) requesting a ride in real time via a smart-phone application, 2) 
viewing the vehicle's real-time location and estimated arrival time while waiting, 3) automatic payment of the ride through the credit card registered with the app, -4 ) where pricing can respond dynamically to demand - and 5) rider and driver rating each other after completion of the ride. In the first step of the analysis, we analyzed how these aspects were implemented in the features of the apps. In the second step, we compared these to the traditional Finnish taxi ride sourcing process and found that the Finnish taxi apps resemble in some aspects the traditional taxi hailing process in Finland, and in some aspects Uber. In the third step, we used the concepts of coercive, normative and mimetic pressures [13] as an analytical lens to help explain the similarities and differences between these features in the three Finnish apps and the Uber app concerning these five aspects. We focus our analysis on the time span from Uber's entry in the Finnish market in November 2014 to the present day situation (February 2018). We analyze how the institutional environment shaped these three Finnish mobile apps.

\subsection{Institutional context: the Finnish taxi service industry}

The idea of taxi services is virtually uniform everywhere: driving a car for a fee to get a customer from point A to point B. However, the Finnish taxi industry differs from the taxi industry in many other countries. Taxi driver-owners are highly unionized as more than $80 \%$ of Finnish taxi drivers belong to the FTOF. Due to the legal framework and high level of unionization, the taxi service industry has provided a rather uniform service everywhere in Finland, costing about the same price at all times. The Finnish government sets the maximum prices for taxis yearly. Finnish taxis are perceived as safe and reliable, even though perhaps costly. All taxi cars have a taximeter and taxi drivers pay taxes loyally. Customers receive receipts for their taxi trips, and the taximeter provides data on all trips. The Finnish taxation office has legal rights to access the taximeter data by request. Due to the aforementioned factors, gray economy has not been a significant factor in the Finnish taxi sector.

Uber entered the Finnish market in November 2014. In August 2017, Uber exited the Finnish market because of being ruled as not conforming to the law in Finland. Uber has announced its return to the Finnish market in July 2018, when the new deregulative Act on Transport Services is enacted in Finland. ${ }^{1}$

\section{Findings}

In the time between November 2014 and February 2018, a number of taxi hailing apps have been introduced in the Finnish market. In this analysis, we focus on the three major - when counting the number of taxis that can be reached with the app - Finnish mobile applications for taxi hailing: App A, App B and App C (pseudonyms).

App B and App C are used by only one dispatch center each. App A, in contrast, has been integrated with 30 Finnish taxi dispatch centers. These centers use five different types of dispatch technologies, and as App A should look and feel the same way to customers all over Finland the different technical requirements set certain limits to the functionalities that have been implemented in App A so far.

${ }^{1}$ https://www.lvm.fi/act-on-transport-services (15.5.2018) 
When we refer to all of these Finnish taxi apps collectively, we refer to them as "Taxi apps", otherwise we refer to them as App A, B and C. Next, we will describe how ride requesting, real-time location, paying, pricing and rating in these Taxi apps differ from or are similar to the Uber app features, and how institutional pressures help explain the resemblance or difference. Fig. 1 summarizes our findings.

\subsection{Requesting a ride}

Starting from the 1950s, customers have been able to call a taxi dispatch center to order a taxi in Finland. Since the beginning of the 21 st century, it was also possible to order a taxi via a text message.

With all Finnish Taxi apps, the passenger uses the mobile application to order a ride. The reason that this additional channel for ordering a car was provided to the customers was related to progressing digitalization and customer expectations in general:

"Everyone knew about [the new entrants]. Uber came to Helsinki in the end of 2014. Taxify was another one that entered in 2014, in Oulu. Those brought the message that people wanted to use [hailing apps]. And if one thinks about our operation model, that you have to call and don't even always know where to call, [having an app] was self-evident..." (Interviewee \#3)."

Mimetic pressure: As digital taxi hailing channels were successful and customers were using them when such channels were available, also the Finnish taxi organizations wanted to provide this to customers.

\subsection{Real-time location}

Already since 2003, the dispatch centers have had location information of the taxis. While the taxi drivers have used GPS navigation for the last two decades, customers did not have access to this information.

All Taxi apps as well as Uber allow for automatic determination of the customer's location. This automatic location determination is used as the assumed address the customer wants to get the taxi to. Once a driver has accepted the requested ride, the estimated arrival time of the taxi is being displayed in all of the Taxi apps as well as the Uber app. The Uber app, App B and App C show the approaching taxi on a map to the customer. App A provides this service only for the Helsinki area, not for other geographic areas in Finland.

Important here is that all app providers see the value of providing real-time location information through the app. Lack of provision is mainly due to difficulties, costs, or coordination challenges related to integration between different dispatch systems:

"A technical challenge is that ... how to provide the user a good and consistent user experience everywhere. Now, when you order a taxi with [App A] in Oulu, you don't see the location information, you only get the arrival estimate. But when you order in Helsinki, you see the car in real time on your screen. This is because the different dispatch centers and other systems have different capabilities. We don't get the same data from different systems. All this scattered data has to be provided consistently to the user." (Interviewee \#3) 
Table 2. Comparison of traditional taxi industry, App A, App B, App C and Uber across the five aspects of the taxi hailing process

\begin{tabular}{|c|c|c|c|c|c|}
\hline & Requesting & $\begin{array}{l}\text { viewing real-time } \\
\text { location on a map }\end{array}$ & $\begin{array}{l}\begin{array}{l}\text { automatic credit card } \\
\text { payment }\end{array} \\
\end{array}$ & surge pricing & rating \\
\hline $\begin{array}{l}\text { Traditional taxi } \\
\text { industry }\end{array}$ & \begin{tabular}{|l|} 
Phone call, text \\
message, \\
hailing taxi \\
down on street
\end{tabular} & $\begin{array}{l}\text { No information about } \\
\text { real-time location of } \\
\text { ordered taxi available to } \\
\text { customer. }\end{array}$ & $\begin{array}{l}\text { Not available. } \\
\text { Payment usually to the } \\
\text { driver either in cash or } \\
\text { via credit card in the taxi. }\end{array}$ & $\begin{array}{l}\text { No. Maximum price for taxi } \\
\text { rides based on measurement } \\
\text { of time and/or distance is } \\
\text { yearly set by Finnish } \\
\text { government. }\end{array}$ & $\begin{array}{l}\text { Feedback given to driver } \\
\text { directly or to "taxi } \\
\text { inspectors" who help } \\
\text { solve conflicts between } \\
\text { customer and driver. }\end{array}$ \\
\hline App A & Mobile app & $\begin{array}{l}\text { Available only in } \\
\text { Helsinki. } \\
\text { In the rest of Finland, } \\
\text { the app displayed the } \\
\text { estimated time of taxi } \\
\text { arrival only. }\end{array}$ & $\begin{array}{l}\text { Not available. } \\
\text { Payment to the driver } \\
\text { either in cash or via credit } \\
\text { card in the taxi. }\end{array}$ & $\begin{array}{l}\text { No. Pricing pre-defined in } \\
\text { adherence to pricing rules set } \\
\text { by Finnish government. }\end{array}$ & $\begin{array}{l}\text { Customers can rate } \\
\text { drivers. Drivers cannot } \\
\text { rate customers. }\end{array}$ \\
\hline App B & Mobile app & Available & $\begin{array}{l}\text { Not available. } \\
\text { Payment to the driver } \\
\text { either in cash or via credit } \\
\text { card in the taxi. }\end{array}$ & $\begin{array}{l}\text { No. Pricing pre-defined in } \\
\text { adherence to pricing rules set } \\
\text { by Finnish government. }\end{array}$ & $\begin{array}{l}\text { Customers can rate } \\
\text { drivers. Drivers cannot } \\
\text { rate customers. }\end{array}$ \\
\hline App C & Mobile app & Available & Available & $\begin{array}{l}\text { No. Pricing pre-defined in } \\
\text { adherence to pricing rules set } \\
\text { by Finnish government. }\end{array}$ & $\begin{array}{l}\text { Customers can rate } \\
\text { drivers. Drivers cannot } \\
\text { rate customers. }\end{array}$ \\
\hline Uber & Mobile app & Available & Available & Surge pricing in use. & $\begin{array}{l}\text { Customers can rate } \\
\text { drivers, and drivers can } \\
\text { rate customers. }\end{array}$ \\
\hline $\begin{array}{l}\text { Institutional } \\
\text { pressure type }\end{array}$ & Mimetic & Coercive & Mimetic & Mimetic & Mimetic; normative \\
\hline
\end{tabular}



Mimetic pressure: Having real-time information about the taxi's location on a map visible for the customer is one of the core features of Uber and other ride hailing apps (e.g., Estonia-based Taxify and US-based Lyft). App B and App C provide this feature, and App A provides it for Helsinki. For App A, this feature is also envisioned to be implemented for the rest of Finland, but technical challenges related to having to integrate several different types of dispatch centers with App A slowed down the implementation of this feature.

\subsection{Paying}

Since the beginning of taxi history in Finland, payment for the ride has been provided directly to the driver at the end of the ride. Card payment has been possible in Finnish taxis since 1980s.

Uber offers only automatic credit card payment through the application. It does not allow a cash payment. In contrast, customers using a Taxi app always have the option to pay for the ride in cash or by credit card directly to the driver in the taxi. Automatic credit card payment is not available in App A and B. Also the dispatch centers using App A would have liked to have this feature in App A. However, due to the technical restrictions stemming from some of the types of dispatch technology used in Finland, this feature has not yet been implemented. App C, in contrast, allows the customer to pay automatically through the app by credit card. Uber was seen as a "role model" with this feature:

Uber showed one thing. They were the first app where you did not have to pay separately. [...] Uber users were praising this. Of course, there were other apps around the world [with app-based payments]. Uber did not invent it, but it succeeded to break through. [...] It started this hype." (Interviewee \#5)

The possibility to implement this feature was one of the reasons why Southern Taxi decided to use their own app instead of App A. They wanted to have full control over the development of features in a situation of rising competition starting from July 2018.

Mimetic pressure: App C was launched in preparation for the fierce competition that is being expected to arise especially in the Helsinki area after the de-regulation of the taxi industry through the new Act on Transport Services. Southern Taxi decided to give up using App A in order to be able to fully make use of the technical abilities and data provided by the dispatch software used in its own dispatch center. Having the opportunity to automatically pay via credit card is one of the core features of Uber and other ride hailing apps (e.g., Estonia-based Taxify and US-based Lyft). Thus, concerning App C, the implementation of this feature can be seen to result from mimetic pressure. In addition, this feature is also wished for and intended for implementation in future in App A, but just as is the case with real-time location information, the technical challenges stemming from having to integrate several different taxi dispatch technologies with App A slowed down the implementation of this feature in App A. 


\subsection{Pricing}

Throughout the history of Finnish taxi, the government of Finland has regulated taxi pricing. Maximum prices for traditional taxi rides are decided upon yearly by the Finnish government. For example, it is defined that taxi companies can bill a fee of around 7 euros if a customer pre-orders a taxi more than $30 \mathrm{~min}$ before the ride. Currently, all taxis in Finland have to have a measurement device - a taximeter - that calculates the price based on the regulation set by the government. Prices for taxi rides ordered with a Finnish Taxi app always correspond to the prices set by the government.

Pricing in Uber, on the other hand, can respond dynamically to demand for and supply of rides. When demand exceeds supply, the service switches to surge pricing mode, where rides can be very costly.

Coercive pressure: As taxi ride pricing is regulated by the Finnish government, none of the Finnish Taxi apps incorporates surge pricing, which is an essential part of Uber's business model and the Uber app. The coercive pressure exercised by the government helps explain on the one hand why pricing is implemented in the same way in all Finnish apps, and on the other hand why Finnish apps do not resemble Uber in regard to pricing.

\subsection{Rating}

Ever since unionization started occurring in 1950s [18], there has been an expectation that Finnish taxi services provide a standardized level of service. This has meant that taxi drivers follow the occupational code of quality service, and by consequence, there is no need to establish a rating system. While customers regularly give feedback about the service, rating has not been part of the profession.

All Taxi apps allow the customer to rate the taxi driver, but not the other way round. Uber, on the other hand, enables a two-way evaluation: drivers evaluate customers, and customers evaluate drivers.

In App A it seems that this driver-customer rating is deliberately left out, as the answer to the question "Does the taxi driver give feedback about the customer?" in the FAQ section on the website of App A states:

"In [App A], drivers do not evaluate customers. The Finnish taxi serves all of its customers with equally high quality".

In addition, several interviewees pointed to the requirement of taxi drivers to be very socially skilled to be able to offer high-quality service to all kinds of customers, also in difficult situations (e.g., picking up someone from the hospital who was just diagnosed with cancer). The general tenor is that taxi drivers are professionals who are skilled in dealing with different types of customers:

"I don't see it important to rate customers. (...) In the end, we need to respect every customer. We need to be humble. I do understand the Uber rating system, that if a customer is difficult, then the customer pays a price for that. But we will not do that. We need to have enough workmanship and flexibility to serve all kinds of customers." (Interviewee \#7) 
Regarding the rating features, both mimetic and normative pressure help explain similarities and differences between Finnish Taxi apps and Uber.

Mimetic pressure: The possibility of customers rating service providers and the other way around has become a common feature in apps and the sharing economy. Taxify, Uber and AirBnB make use of this feature, and in the case of customers being able to rate drivers, it seems that mimetic pressure is at play.

Normative pressure: Where Uber enforces that drivers rate their customer, this feature is (deliberately) left out from Finnish Taxi apps. It seems that the decision to exclude the driver-customer rating is a result of certain standards the taxi associations have set for the taxi driver occupation and represents an example of how normative pressure affects taxi app features.

\subsection{Summary}

Fig. 1 summarizes our findings. We show for each feature whether Finnish Taxi apps resemble the traditional Finnish taxi hailing process (i.e., the grey bar crosses the line between "Traditional" and "Finnish Taxi apps") or Uber (i.e., the grey bar crosses the line between "Finnish Taxi apps" and "Uber"). For two features - real-time location information and paying - some apps resemble the traditional taxi hailing process, whereas other apps resemble Uber. Even though for App A the wish exists to provide real-time location information and automatic credit card payment, mostly technical challenges and limitations are reasons for why the app differs from Uber. Rating is separated into whether customers can rate drivers (Customer $\rightarrow$ Driver) and whether drivers can rate customers (Driver -> Customer).

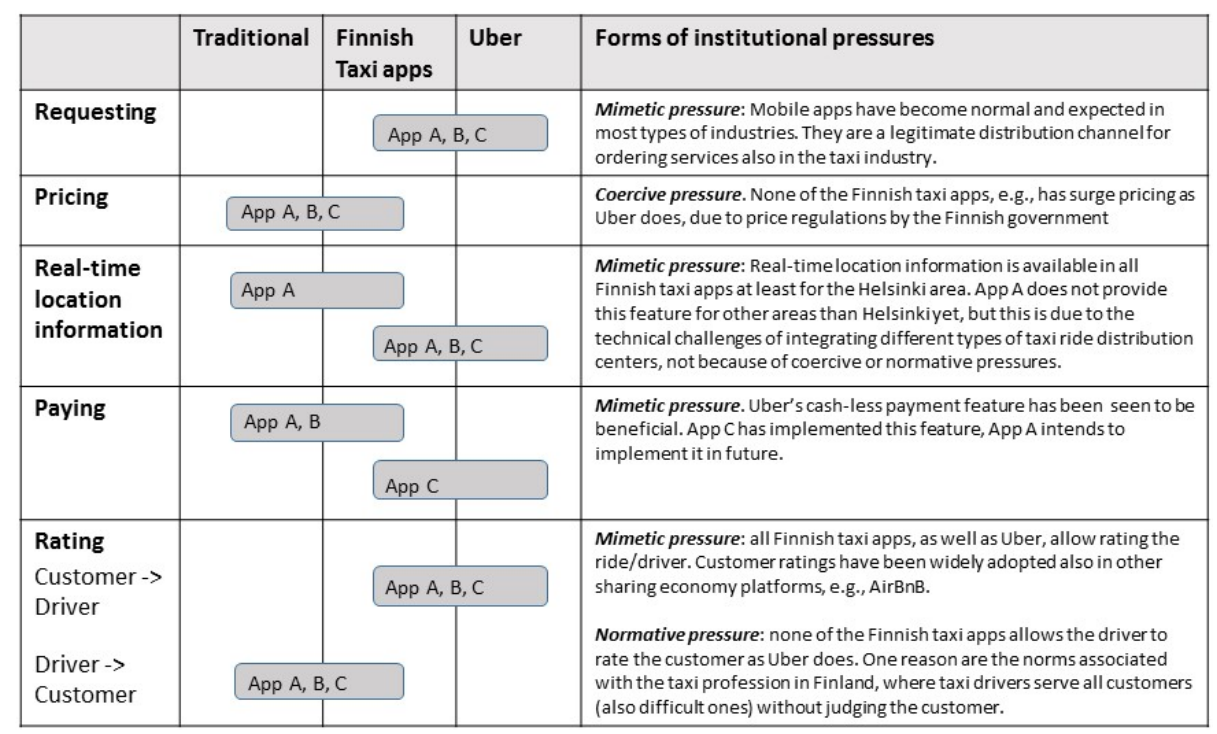

Fig. 1. Coercive, normative, and mimetic pressures in the features of Finnish taxi hailing apps 


\section{Discussion}

We set out to answer how institutional pressures are implicated in the feature functionalities of Finnish taxi hailing apps. With our analysis in the previous section, we demonstrated how different types of institutional pressures help explain similarities and differences between the Finnish mobile apps on the one hand, and features of the mobile app provided by the disruptive model of Uber (cf. [20,21]) - on the other hand. Our main contribution lies in illustrating how mobile applications as IT artefacts are carriers of institutional pressures that materialize in the features of the IT artifact.

Previous research has already addressed the encodement of institutional logics into IT systems [4] and argued for applying institutional theory as a historical understanding of how certain IT artefacts come about over time [9]. With this study, we contribute to research on institutionalization and IT by illustrating how features of mobile applications are affected by three types of institutional pressures: mimetic, coercive and normative. The Uber app has been praised by customers and competitors alike. We found that mimetic pressures are reflected in certain features of Finnish mobile apps (e.g., real-time location information and payment), most clearly in App C which prepares for the increased competition that is expected to arise after the de-regulation of the Finnish taxi industry in July 2018. We found that the Finnish government's coercive pressure in form of taxi price regulation is reflected in the pricing feature of Finnish Taxi apps. Coercive pressures apply to all organizations in a specific field [13] - in this case the Finnish taxi industry. This helps explain why all Finnish apps differ from Uber regarding pricing. We also found that normative pressures in form of certain standards regarding the taxi driver profession and upheld by the FTOF and taxi organizations are reflected in not allowing drivers to rate their customers in Finnish Taxi apps. Our findings are supported by Mignerat and Rivard [15]. They found that in IT innovation processes, coercive pressures are exercised, amongst others, by governments, and mimetic pressures, for example, by competitors (which Uber can be seen to represent).

We also contribute to research on the relationship between institutional environment and IT artefacts by taking a somewhat different approach than extant research. Much of previous research on institutional theory and IS focused on the effects of the institutional environment on IT adoption and use [22-24], or the institutional effects in IT innovation and interaction between IT and institutions [15]. We, in contrast, focused on the effect of institutional pressures on mobile app features. Just as Rajão and Hayes [9] found that the design of IT artefacts tends to reflect the currently dominant conceptions of control, we found that the design of mobile apps (which are IT artefacts) reflects different institutional pressures.

Specifically in the Finnish taxi industry, there is a long history of the profession of taxi drivers, and taxi services are generally of a high standard. The Finnish taxi industry thus differs greatly from, e.g., the North American taxi services, which have been described as substandard [5].

With our research, we applied principles of the institutional theory from the organizational level to the mobile app feature level. Institutional theory has been applied to explain why organizations start to resemble each other [13]. We showed that the concept of institutional pressures can explain both similarities and differences 
between features of IT artifacts. Similarly to how institutions are "carriers of histories" [25], IT artifacts such as mobile applications are carriers of institutional pressures.

\section{Conclusion}

In this paper, we applied the three types of institutional pressures (normative, mimetic, coercive) as an analytical lens to help explain why three Finnish taxi hailing apps on the one hand resembled - and on the other hand differ from - the Uber app. We focused on five app features: 1) ride requesting, 2) pricing, 3) providing real-time location information, 4) paying, and 5) rating.

We found that 1) coercive pressures exercised from the Finnish government help explain why pricing in all three Finnish apps resembles each other whereas it differs from Uber, 2) normative pressures explain why none of the Finnish apps allows drivers to rate customers, and 3) that mimetic pressures help explain resemblances between Finnish apps and Uber regarding ride requesting, real-time location information, and customers rating drivers.

We contribute to the IT and institutionalization research stream by illustrating how mobile applications as IT artefacts can be seen as carriers of institutional pressures that materialize in the features they provide.

This study also has several limitations. First, our analysis focuses on Finland only. Second, we focus on a customer and service-perspective. Thus, we did not focus on supply-side issues or (de-)regulation in this paper (e.g., [4], [26]).

Our study opens up avenues for future research. More research is needed to support or corroborate our findings, e.g., by conducting a similar analysis in another industry where a "disruptor" entered a highly regulated market with a mobile app. From the Finnish perspective, the de-regulation of the taxi market in July 2018 can be seen as a case of re-creation of an institution [27]. This provides interesting research opportunities: will future Finnish taxi hailing apps show more signs of mimetic pressure, with Finnish taxi apps starting to resemble more and more Uber-type applications (e.g., by incorporating surge pricing)? Will we still see signs of normative pressures where taxi apps contain values currently held by the taxi driver profession overall? We call for further empirical research on and theorization of changes in the taxi industry over longer time spans (e.g., [9]), making use of historical approaches and longitudinal data.

\section{References}

1. Stone, B.: The Upstarts: How Uber, Airbnb and the Killer Companies of the New Silicon Valley are Changing the World. Bantam Press, London (2017)

2. McGregor, M., Brown, B., Glöss, M.: Disrupting the cab: Uber, ridesharing and the taxi industry. Journal of Peer Production (2015)

3. Hacker, P.: UberPop, UberBlack, and the Regulation of Digital Platforms after the Asociación Profesional Elite Taxi Judgment of the CJEU. European Review of Contract Law 14, 80-96 (2018)

4. Tucker, E.: Uber and the Unmaking and Remaking of Taxi Capitalisms: Technology, Law and Resistance in Historical Perspective. In: McKee, D., Makela, F., Scassa, T. (eds.) 
Law and the "Sharing Economy": Regulating Online Market Platforms. University of Ottawa Press, Ottawa (2018)

5. Cramer, J., Krueger, A.B.: Disruptive Change in the Taxi Business: The Case of Uber. Am. Econ. Rev. 106, 177-182 (2016)

6. Um, S., Yoo, Y., Berente, N., Lyytinen, K.: Digital Artifacts as Institutional Attractors: A Systems Biology Perspective on Change in Organizational Routines. In: Bhattacherjee, A., Fitzgerald, B. (eds.) Shaping the Future of ICT Research. Methods and Approaches, pp. 195-209. Springer, Berlin, Heidelberg (2012)

7. Boxenbaum, E., Jonsson, S.: Isomorphism, Diffusion and Decoupling: Concept Evolution and Theoretical Challenges. In: Greenwood, R., Oliver, C., Lawrence, T.B., Meyer, R.E. (eds.) The SAGE Handbook of Organizational Institutionalism, pp. 78-98. Sage, London (2008)

8. Gosain, S.: Enterprise information systems as objects and carriers of institutional forces: the new iron cage? J. Assoc. Inf. Syst. 5, 6 (2004)

9. Rajão, R., Hayes, N.: Conceptions of control and IT artefacts: an institutional account of the Amazon rainforest monitoring system. J. Inf. Technol. 24, 320-331 (2009)

10. Orlikowski, W.J., Iacono, C.S.: Research Commentary: Desperately Seeking the "IT" in IT Research - A Call to Theorizing the IT Artifact. Inf. Syst. Res. 12, 121-134 (2001)

11. Bekken, J.-T.: Experiences with (De-) Regulation in the European Taxi Industry. Organisation for Economic Co-operation and Development (OECD) (2007)

12. Scott, W.R.: Institutions and Organization: Ideas, Interests, and Identities. Sage, Thousand Oaks (2014)

13. DiMaggio, P., Powell, W.W.: The iron cage revisited: Collective rationality and institutional isomorphism in organizational fields. Am. Sociol. Rev. 48, 147-160 (1983)

14. Strang, D., Soule, S.A.: Diffusion in organizations and social movements: From hybrid corn to poison pills. Annu. Rev. Sociol. 24, 265-290 (1998)

15. Mignerat, M., Rivard, S.: Positioning the institutional perspective in information systems research. J. Inf. Technol. 24, 369-391 (2009)

16. Hasselbladh, H., Kallinikos, J.: The project of rationalization: a critique and reappraisal of neo-institutionalism in organization studies. Organ. Stud. 21, 697-720 (2000)

17. Yin, R.K.: Case Study Research: Design and Methods. Sage Publications, Thousand Oaks, California (2009)

18. Mauranen, T.: Taksi! Matka suomalaisen taksin historiaan. Suomen taksiliitto ry, Forssa (1995)

19. Hodges, G.R.G.: Taxi! A Social History of the New York City Cabdriver. The Johns Hopkins University Press, Baltimore (2007)

20. Rayle, L., Dai, D., Chan, N., Cervero, R., Shaheen, S.: Just a better taxi? A surveybased comparison of taxis, transit, and ridesourcing services in San Francisco. Transport Policy 45, 168-178 (2016)

21. Crittenden, A.B., Crittenden, V.L., Crittenden, W.F.: Industry Transformation via Channel Disruption. J. Market. Channels 24, 13-26 (2017)

22. Zorn, T.E., Flanagin, A.J., Shoham, M.D.: Institutional and Noninstitutional Influences on Information and Communication Technology Adoption and Use Among Nonprofit Organizations. Hum. Commun. Res. 37, 1-33 (2011)

23. Magnier-Watanabe, R.: An Institutional Perspective of Mobile Payment Adoption: The Case of Japan. 47th Hawaii International Conference on System Sciences (HICSS), pp. 1043-1052 (2014)

24. Lai, K.-h., Wong, C.W.Y., Cheng, T.C.E.: Institutional isomorphism and the adoption of information technology for supply chain management. Comput. Ind. 57, 93-98 (2006) 
25. David, P.A.: Why are institutions the 'carriers of history'?: Path dependence and the evolution of conventions, organizations and institutions. Struct. Change Econ. Dynam. 5, 205-220 (1994)

26. Frizell, S.: A Historical Argument Against Uber: Taxi Regulations Are There for a Reason. Time.com N.PAG (2014)

27. Lawrence, T.B., Suddaby, R., Leca, B. (eds.): Institutional work: Actors and agency in institutional studies of organizations. Cambridge University Press, Cambridge (2009) 